\title{
Use of Recycled Materials in Road Construction
}

\author{
M. Abukhettala \\ Department of Civil Engineering, University of Ottawa \\ 161 Louis Pasteur, K1N 6N5, Ottawa, ON, Canada \\ Mabuk023@uottawa.ca;
}

\begin{abstract}
With the evolution of the road industry and growing traffic on roads, construction materials have also been evolved and more unconventional ingredients have been incorporated. The rationales was the scarcity of conventional natural materials and the jeopardized environment which have underpinned the tendency towards evaluation other materials resources to be incorporated in the road industry. The inclusion of such materials entails several secondary and tertiary materials. Several waste by-products and materials have been investigated, assessed, evaluated for utilizations and practiced in the field. Depending on the attributes of the characteristics of the recycled material, the inclusion varies. Some recycled material have been proven to possess preferable properties over the other and have performed satisfactorily in the field. However, there are numerous concerns regarding such incorporation based on both laboratory experimental, and field observations which have turned out to be of the essence for further in-depth studies. Reclaimed asphalt pavement, recycled concrete aggregates, plastic wastes, scrap tires, mine wastes, recycled crushed glass, foundry sand, coal combustion products as fly ash, bottom ash, and pond ash, steel slag, oil sand, oil shale sand, lateritic soil, are amidst the long list. It is believed that magnificent preservation of natural and precious resources would be attained from the inclusion of secondary and tertiary materials in road construction. Nonetheless, without rigorous cooperation between the academia and the industry and educating people who are in routinely interact with paving activities, several performance-related issues would not be resolved and would remain in existence. This paper present a literature review report on the most viable recycled materials currently in practice by the industry and it aims towards developing a noble idea on better inclusion of a recycled material in the road industry.
\end{abstract}

Keywords: Asphalt pavements - Aggregates - Asphalt binder - Recycling - Waste by-products.

\section{Introduction}

The evolution of road industry and the tremendous surge in number of vehicles on roads has been a rationale that has promoted exploiting all viable available resources to build better roads of prolonged service life. Incorporating unconventional construction material in the road construction commenced in the 80's where conventional raw materials such as bitumen, crushed aggregates, and unbound aggregates mixtures began to scarce [1]. The process of producing aggregates materials has been causing extreme disruption to the environment [2] and to the economic owing to the severely depletion the natural resources [3]. Furthermore, the alarming rate of increased waste production is what underpin the efforts to investigate the potential incorporation of various by-products in road construction [4]. The most dominant recycling materials that are in practice at present include plastic wastes, scrap tires, foundry sand, bottom and fly ashes, oil sand, marble dust, recycled concrete aggregates, reclaimed asphalt pavement, steel slag. Much research has been conducted in this directions [5]. And still there are ongoing researches and field studies continue the investigation for better utilization of these recycled materials. Aside from benefits and promising research recommendations and practical results obtained from using waste material as substitutions to natural raw materials, several barriers have roadblocked the employment of recycled material by virtue of environmental concerns and the lack of real field experience with such materials $[1,6]$. Certain recycled material and waste by-products possess considerable salient properties over others and great benefits would be acquired when characterized properly and incorporated with some other construction materials [7].

Recycling materials have been reported to be utilized in different composition in different layers of road structure from the top surfacing layer to the underneath layers [8]. The processing cost, the engineering properties, the evidence that demonstrate the viability of the material and its positive impact on the long-term performance of the road construction works are what characterizes and favours the use of that specific recycled waste material [8]. It is of the essence to properly understand the behaviour of any recycled by-products, and investigate the influence on the proposed inclusion with a 
construction material in order to come with a suitable and viable utilization with regards to type of material and the employed dosage. [3]

The deficiencies and drawbacks in the quality of produced asphalt binder from native crude-oil producers have its repercussions on the performance of asphalt pavement under oscillating traffic loads [9]. The quality and price of asphalt cement use in the road industry has been another pile of advocating the quest for anther replacement. A supporting evidence for the bitumen-related issue is the concern in Ontario over the usage of refined motor oil with the asphalt cement. It was stated that about $50 \%$ of used asphalt cement is the road construction contains traces of remaining substance from the refining process of engine motor oil. This is a disastrous course of action which transmute the rheological properties of the asphalt cement and lead to unfavourable HMA performance [10]. Shortfalls and scarcity of natural quality aggregates, heavy imposed traffic loads, and extreme environmental conditions have taken tolls on road paving industry [9]. Researches on existing recycling material was to valorise the utilization of recycled materials in road constructions and improve the longterm performance of asphalt pavement. [11]. any successful applications of recycled materials in road construction works oriented towards the efforts of achieving a sustainable pavement construction. [12]. According to the ministry of national resources on the status of aggregates in Ontario, the industry still reluctant in utilizing currently suggested materials and the rationale was ascribed to the shortage of supportive practical and field experience and to some deficiencies- in the performance of implemented materials. Only $18 \%$ to $19 \%$ of the total annual required aggregates for road construction was surrogated by recycled aggregates that represented in total a 130 Million tons according to the state of aggregates report issued by ministry of the national resource of Ontario in 2009 [6].

\section{Waste Materials \& By-Products in Road Construction}

\subsection{Introduction}

The pivotal thrust of utilizing waste materials into road construction field is diminishing the detrimental repercussions of processing natural materials on the environment, to alleviate the burden on authorities in both developing and developed countries in providing landfills and setting provisions for such wastes, and to reaffirm the commitment of the industry towards better road services and riding quality. Besides, the scarcity of the natural resources is also an intuitive rationale that underpins utilizations. Several experimental and research studies have been dedicated to investigating potential incorporating of waste materials in road construction field. Many pieces of research have proven a success in reusing and recycling of some compositions of these waste materials in pavement structures and others are still undergoing comprehensive research studies to further shed the light on what can be gained from their recycling into pavement constructions. Due to some stringent knowledge and shortage of funding for in-depth analysis of utilizing the some waste materials in the utmost beneficial way, the waste material is a core problematic issue to governmental institutions and transportation legislation authorities in several parts of the world. International cooperation is a key factor in protecting the environment through diminishing the greenhouse gasses emission and preserving natural resource via exploiting viable recycled materials into the construction field and giving focus on assessing approaches in employing such materials [16].

The Non-conventional material is defined as the material that does not possess the required properties as per the traditional specifications [17]. With the unending demand for aggregates material in road construction, the scarcity of accepted quality material as well as the urge in preserving natural resources, there has become urgent necessity for inclusion secondary material and waste by-products in road construction field. Several waste recyclable materials have been incorporated in various projects all over the globe and displayed the opportunity in not only budgetary saving but also in protecting the environment. Road responses and long-term performance rely exhaustively on serious of attributes of the incorporated material in the compositions of the structure, it is an overarching issue to thoroughly comprehend the behaviour and pattern of these materials and their transmutation effects when used on its own or assorted with other materials and used

in road pavement structure. It is believed that the responses to the increasingly huge demand on providing substitutions for natural materials in road construction has been efficiently responsive and reflected mounds of researches have been dedicated to executing feasibility studies on using these surrogate material with the consideration of sustainability perspective for both the environment and the economic [18]. 


\subsection{Types of recycled Materials in use for Road Constructions}

\subsubsection{Plastic Wastes}

Most littered plastic are rich in polymers [21]. It can be used either as a stabilizing agent in soil and subgrade applications or as an additive to aggregates blends in hot mix asphalt pavement [22]. It is either added to the binder as pellets in the rate of $0.25-0.5 \%$ of binder weight in the wet approach or to the aggregates in the dry approach [20]. All in all, the wet method outstrips the dry method in easiness and applied shearing forces to ensure dispersing of the plastic chips [21]. HDPE is preferred over LDPE in enhancing HMA mechanistic properties [23]. The higher the rate of added plastic less susceptible to temperature the bitumen becomes [24].It improves stripping resistance [24]. 30\% of LDPE in the dry method developed the mixture stability and in the rate of retained tensile strength [20]. HDPE with HMA posed improvement to deformation resistance, high stability, and a low flow value. An optimum HDPE rate was about 5\% for higher acceptable performance and reduced cost of HMA [25]. HDPE revealed better properties of subgrade when added at $0.25 \%$ [26]. Incorporating plastic up to $25 \%$ resulted in enhanced HMA performance in terms of stability, skidding, deformation resistance, fatigue, and no defects observed [27]. In Argentina, 2\% of the flaked PE demonstrated an optimum performance of the mixtures [25]. 60/70 PEN examined in Nigeria with Polyethylene terephthalate from a plastic bottle and mixture properties tremendously improved [28]. Recycled plastic pins RPPs derived from plastic wastes have been utilized in stabilizing embankments. [29]. Plastic-derived wax mixture have been laid in Vancouver. The mixture is produced by refining recyclable plastic into wax substance. In 2012, the new modified mixture has been lied on roads after a comprehensive testing on small sections in the city to assess the quality of the produced mixture. Advantages include reduced mixing temperature that consequently minimize the carbon footprint. Opponents believe that CIPR and foamed asphalt have been found effectively suitable, efficient, and less expensive when compared with the plastic derived warm mix asphalt technique. The concern is the longterm performance of the warm plastic modified asphalt mixture which remains questionable until a comprehensive evaluation is carried out [9].

\subsubsection{Recycled Asphalt Shingles}

Asphalt shingles are categorized into two groups, fiberglass, and organic shingles. Both types are composed of varying rates of mineral fibres, mineral fillers, and hard rock granules (ultra-tiny particles ceramic - coated granule) in addition to asphalt cement [30] of an average percentage of $30 \%$ by total mass [31]. In the province of Ontario in Canada, organic shingles have recently become produced and a harder bitumen type than that commonly used in HMA works covered with aggregates granules of high quality [6]. However, each manufacturer would have a relatively varied composition for the produced asphalt shingles. [32]. Fiberglass shingles are of an asphalt cement rate of about $15 \%$ less than that contained in the organic shingles, which in-turns makes fiberglass shingles cheaper and preferable over organic ones [30]. The content of asphalt cement in Recycled asphalt shingles ranges from 19\% to 31\% [33]. The aim of utilizing asphalt shingles in road construction is to reduce amount of virgin binder [34].

Manufacture scrap and tear-offs scrap shingles are called post manufacturing, or pre-consumer and post-consumer shingles respectively [34]. It should be taken into account when considering recycled shingles in road construction works to keep shingles of different sources assorted for proper design and implementations. The range of AC content varied from 14.6 to $36.7 \%$ in the RAS from different sources used in that study which deemed considerably influential [33]. Asphalt binder from tear-off shingles is considered stiffer than the binder from pre-consumer shingles due to aging and environmental exposure issue [34]. Tensile strength, rutting resistance, resistance to moisture damages have been also reported to be enhanced. However, the resistance to fatigue and thermal cracking has to be given a focus. The use of recycled asphalt shingles is limited by the percentage of $5 \%$ of the total weight of the mixture from a performance perspective as it is made of an air-blown asphalt binder that stands out for its highly viscous property compared to its virgin counterpart used in the hot mix asphalt mixture [34]. There are several concerns over incorporating RAS \& RAP is asphalt pavements resulting from aging and brittleness characteristics of such material which proved to have an adverse low-temperature performance impact on asphalt pavement [24]. RAS modified mixture demonstrated unfavorable performance at the lower temperature, the study suggested further investigation on this issue for the OGFC mixture. Field evaluation was only done visually [32].

To conquer thermal cracking deficiency, it is suggested to use less stiff asphalt cement when RAS is in use [24]. A rate of $5 \%$ of either post manufacturing or tear-offs shingles reported to be sufficient in providing an asphalt mixture that complied with specification requirements [34]. However, only 3\% of recycled shingle is needed to be added to RAP modified mix to produce a more rutting, fatigue and thermal crack-resistant RAP modified asphalt mixture [31]. The inclusion of RAS 
into asphalt mixtures at varying rates of $5 \%$ to $10 \%$ displayed that as the rate of RAS increased, tensile strength declined [24, 30, 33] and resistance of thermal cracking also dropped [34]. HMA is believed to exhibit more durability when RAS is used [34]. This was also concluded when a rate of 5-10\% of asphalt shingles was used [30]. One of the very few studies on utilizing RAS \& RAP in asphalt pavement in Canada concluded that RAS was found to be more influential on the properties of asphalt mixture than RAP and revealed that the investigated mixes proved better performance when an amount of $3 \%$ of less utilized with RAP-modified HMA as per Ontario asphalt pavement requirements [31]. Cracks were observed over asphalt pavements modified with a high rate of RAS [34]. However, Field observations on a major highway paved with a modified open graded frictional course asphalt mixture exhibited an appreciated performance after few years of in- service. Pavement showed no indication of surface defects or failure over the period of 2-year and a half of observations. Nonetheless, observations were made by a visual inspection rather than a long-term performance evaluation procedure which should have been conducted for better assessment of the evolving condition of the pavement [32].

\subsubsection{Reclaimed Asphalt Pavement}

The rate of utilizing reclaimed asphalt pavement in HMA and base material in Ontario has been reported to be as low as $8 \%$ of the total recycled material used between 2004 and 2006 [6].The characteristics of RAP vary from one source to another according to the type and properties of aggregates material, binder content, binder stiffness, of the scarified pavement. The concentration of RAP in the new asphalt mixture is considered pivotal factor influencing performance of HMA. It has been reported that the performance of an asphalt pavement made of new material would be as equally satisfying as that composed of a low to intermediate rate of $25 \%$ RAP. Technically, modification to the binder grade in the asphalt mixture, especially the low temperature grade, does not need much concern when RAP is used in less than $15 \%$ of the total weight of the mixtures. It has been reported that the performance of a new asphalt pavement would be as equally acceptable as that composed of a low to intermediate rate of $25 \%$ RAP [35]. The implications of using a rate of more than $20 \%$ of RAP on the grade of binder is significantly higher than that when the rate is in the low range $(<20 \%)$ [36]. It was indicated in literature that between $15-25 \%$ of RAP in the mix needs a modification of reducing the grade on both low and high temperature by $6^{\circ} \mathrm{C}$. [35]. However, when a combination of an average rate of $20 \%$ RAP along with $3 \%$ RAS is used, low temperature grade of asphalt cement goes up by $6^{\circ} \mathrm{C}$ and a reduction in the low temperature performance grade of asphalt cement was suggested [33]. The maximum permitted rate of RAP in HMA application as per MTO specification requirements is 30\% [6]. It is believed that higher added amount of RAP in HMA application is the reasons of premature road failure which needs to be examined by routine testing on supplied HMA by contactors. According to Simon Hesp, contracts tend to use higher rate of RAP than permitted which turns to destroy an investment in millions of dollars for a saving of few thousand dollars and educating the people in the industry is considered a key in successful implementation of RAP in HMA [37].

\subsubsection{Crumb Rubber "Scrap tires"}

Whether it is processed in either the wet or dry approach, the crumbed rubber used in asphalt surfacing applications has several other advantages other than improved resistance to skidding. It also provides asphalt mixtures with high shear strength, which is favourable in withstanding imposed traffic load and preventing the occurrence of rutting in the underneath pavement layers. [20,38]

In addition, during freezing and thawing cycles in cold weather conditions, the presence of scrap rubber in the underneath layer compositions plays a crucial role in reducing the frost penetration level [20]. Some other benefits of using crumbed rubber in road construction applications include but not limited to rendered temperature susceptibility, fostered rutting and fatigue resistance, and increased stability and reduced flow value ( up to a rate of $10 \%$ of crumb rubber ) and improving stripping resistance [50]. When added to asphalt binder up to a percentage of 30\%, significant enhancement in properties such as weathering and stripping resistance have been achieved [20].

\subsubsection{Foundry sands}

It is a by-product of ferrous and nonferrous metal casting industry and classified as a fine grained material consist of a high-quality silica of a uniform size and a considerable cleanliness [46]. Literature mentioned that sand is re-used at the foundries for as many times as it becomes possibly impractical to do so, then it is deposited as a waste sand foundry. It is at this stage when considering it for road works [47]. This material has been utilizing in HMA, subbase, embankments, and in backfill material as flowable fills. Its high clay content makes it not viable at high water level or poor drainage locations .Nonferrous foundries is not recommended for HMA due to high amount of heavy metallic substances [47]. In Ontario, 
Canada, most moulding sand is being returned to foundry factories for reusing and the incorporation was limited to a maximum rate of $15 \%$ in asphalt mixtures because of some moisture-induced damage concerns. However, this material is not recommended to be used in the base/subbase application anymore as some technical and environmental ramifications have been reported [6]. A rate of 5.5\% cement added for foundry-modified subbase and results were encouraging and satisfied [47]. Another findings showed that inclusion of 5-15\% in base-subbase did not alter neither the OMC nor MDD. However, the resilient modulus results were much less that of the referenced base mixtures and further investigation on performance of modified base-subbase materials was suggested [15]. In CIPR mixtures, foundry sand was found of high potential characteristics to surrogate the natural aggregates in the CIPR mixture despite the fact that less improvement has been gained in strength, stiffness and rutting resistance of the foamed asphalt mixture with foundry than the bottom ash [18]

\subsubsection{Coal Combustion Products / Supplementary Cementitious Material}

This includes fly ash, bottom ash/Boiler slag, pond ash, oil Sand, petroleum-contaminated soil, oil shale ash, and Brake Shoes Fine. The modest rate of heavy metals in fly ash [18] and ultra-tiny particles make fly ash as a mineral filler in HMA is viable. It can be of either type $\mathrm{C}$, which is of high calcium content, or type $\mathrm{E}$ of reduced calcium content. Subgrade properties improved with the addition of 2 to $12 \%$ of fly ash [3]. A rate of $10 \%$ of Type C used with RAP material in base material and conspiracy manifested between lab and field results in terms if CBR and resiliency value [48]. The addition of $40 \%$ of fly ash to the RAP modified mixture with $20 \%$ new aggregates would be conceivable suitable for subbase and base course material in light traffic pavements [49]. Fly ash can be used in a rate reaches 8-12\% when compared to 1-3\% of lime and cement in CIPR mixtures and about $25 \%$ saving is attained [50]. In cement stabilized base, a rate of $25 \%$ of $12 \%$ cement should be maintained to have the required compressive strength in compliance [51]. It was found to develop considerable moisture-damage resistance with inferior quality aggregates mixed with regular PG binder as compared with that of a superior quality aggregates with polymer modified PG binder [52].

Bottom ash/Boiler slag has the advantages of being of high resistance to skidding due to its angular glassy surface [8]. Ash obtained from the blast furnace is referred to as furnace bottom ash [18]. Literature states that the fly ash is preferred over bottom ash in road construction [53]. However, bottom ash usage overweight the fly ash in terms of the instant increase in resiliency [53]. Mississauga and Brampton produce annually 30000 tons of bottom ash and 3000 tons of fly ash. Only $10 \%$ in permitted for use in HMA [6]. There has been a leaching issue concern with this ash and vetrification in proposed to tackle it. The vetrified ash is of glassy texture, is what is to be incorporated in asphalt pavement as aggregates. It is a water-hating material would greatly reduce the amount of asphalt cement needed to get the desirable performance properties. Tensile strength and resistance to deformation enhance with the addition of bottom ash and further analysis needs to be undertaken to assess resistance to stripping characteristics [16].

Pond ash is a slurry of water and ash dumped at lagoons and characterized by its non-crystalline appearance. It is most often modified with other additives such as lime and fiber to enhance the properties. As the rate of fiber $\&$ lime mixed with the ash increased, vertical compressive strain and horizontal tensile strain imposed on base course and subgrade layers decreased. Thus, the stiffness of pavement increased with the addition rate of fiber and lime [54]. Again, it is justified to further investigate the influence of using pond ash on CBR value of the subbase material.

Oil, tar, or bituminous sand is a by-product of oil sand refining process crude oil production and accumulated naturally as deposit mixture of sand, clay, water with a highly viscous asphalt cement which reaches $13 \%$ in Utah. The world biggest source of oil sand debris is located in Alberta. In the US, owing to the size of deposits, availability of water for the extraction process, compositions of deposit are some of the obstacles hinder exploiting this oil sand. The first use of this material goes back to 1913 in Canada. When used in Gap HMA, results demonstrated poor rutting resistance and mixing temperature, i.e., $104^{\circ} \mathrm{C}$ was lower than that for conventional HMA [55]. Further comprehensive analysis of incorporating oil sand in HMA is needed.

Ash from oil shale production is deemed a valuable additive to improve rheology of asphalt cement. Examining the inclusion of 0 to $20 \%$ at an increment of $5 \%$ by means of dynamic shear rheometer and rotational viscometer test at high temperature was executed. Shear modulus increased with the increase in used rate. However, elastic behavior of the modified binder was stagnated as indicated on phase angles results. Hence, shale ash did not have an impact on low-temperature behavior of the virgin binder. Examining other binder graded was suggested and furthered analyzed on lower temperature performance required [13].

Brakes shoes dust from an automotive industry was examined in china as a filling material in HMA at rates varies from 0 to $7.5 \%$ at an increment of $2.5 \%$. Dynamic modulus from t SPT demonstrated a rise in the modulus at a high 
temperature of $40^{\circ} \mathrm{C}$ and a decline at a low temperature of $5^{\circ} \mathrm{C}$. Only at a rate of $2.5 \%$, the tensile strength was improved as indicated by the IDT. Despite the fact that resistance to deformation was not discernable, a conclusion was made on the usage of $2.5 \%$ of brake shoes powdered material as a filling material in HMA [56].

\section{Conclusion}

Despite all researches on potential use of recycled material in road structure, yet there is mounds of concerns and knowledge gaps that require intensive investigation and assessment to the interest of building better roads and preserving natural resources. In should be emphasized other potential recycled materials for road construction such as mine wastes [5357] were not discussed in this paper.

\section{References}

[1] M. Tuncan, A. Tuncan, \& A. Cetin, "The use of waste materials in asphalt concrete mixtures," Waste management \& research, vol. 21, no. 2, pp. 83-92, 2003.

[2] H. Akbulut \& C. Gürer, "Use of aggregates produced from marble quarry waste in asphalt pavements," Building and Environment, vol. 42, no. 5, pp. 1921-1930, 2007.

[3] A. Athanasopoulou \& G. Kollaros, "Fly ash exploited in pavement layers in environmentally friendly ways," Toxicological \& Environmental Chemistry, vol. 97, no. 1, pp. 43-50, 2015.

[4] S. Paranavithana \& A. Mohajerani, "Effects of recycled concrete aggregates on properties of asphalt concrete," Resources, Conservation and Recycling, vol. 48, no. 1, pp. 1-12, 2006.

[5] J. M. Reid, "The use of alternative materials in road construction," in International Symposium on Unbound Aggregates in Roads-UNBAR, 2000, vol. 5.

[6] LVM-JEGEL, "State of The Aggregate Resource In Ontario Study (SAROS) - Paper 4. Ontario: Queen's Printer for Ontario," 2009. Print.

[7] S. W. Lee \& K. L. Fishman, "Waste products as highway materials in flexible pavement system," Journal of transportation engineering, vol. 119, no. 3, pp. 433-449, 1993.

[8] A. El-Assaly \& R. Ellis, "Evaluation of recycling waste materials and by-products in highway construction," The International Journal of Sustainable Development \& World Ecology, vol. 8, no. 4, pp. 299-308, 2001.

[9] C. Holbert, J. Drelich, W. Zmierczak, \& J. D. Miller, "Viscosity of bitumen-crumb rubber blend (new paving material)," Petroleum science and technology, vol. 15, no. 5-6, pp. 523-543, 1997.

[10] Uses of Asphalt. (n.d.). [Online]. Available: http://www.eapa.org/asphalt.php?c=78.

[11] M. Pettinari \& A. Simone, "Effect of crumb rubber gradation on a rubberized cold recycled mixture for road pavements," Materials \& Design, vol. 85, pp. 598-606, 2015.

[12] S. Saride, A. J. Puppala, \& R. Williammee, “Civil Engineers Ground Improvement 163 February 2010 Issue GI1,” sta, vol. 717, no. 715, 2010.

[13] M. Saltan \& F. S. Findık, "Stabilization of subbase layer materials with waste pumice in flexible pavement," Building and Environment, vol. 43, no. 4, pp. 415-421, 2008.

[14] A. Emersleben \& N. Meyer, "The use of recycled glass for the construction of pavements," in GeoCongress 2012@ sState of the Art and Practice in Geotechnical Engineering, 2012, pp. 1642-1649.

[15] D. H. Kang, S. C. Gupta, A. Z. Ranaivoson, J. Siekmeier, \& R. Roberson, "Recycled materials as substitutes for virgin aggregates in road construction: I. Hydraulic and mechanical characteristics," Soil Science Society of America Journal, vol. 75, no. 4, pp. 1265-1275, 2011.

[16] M. Bassani, E. Santagata, O. Baglieri, M. Ferraris, M. Salvo, \& A. Ventrella, "Use of vitrified bottom ashes of municipal solid waste incinerators in bituminous mixtures in substitution of natural sands," Advances in Applied Ceramics, vol. 108 , no. 1 , pp. 33-43, 2009.

[17] L. R. de Rezende, M. O. Marques, \& N. L. da Cunha, "The use of non-conventional materials in asphalt pavements base," Road Materials and Pavement Design, vol. 16, no. 4, pp. 799-814, 2015.

[18] M. Pasetto \& N. Baldo, "Laboratory investigation on foamed bitumen bound mixtures made with steel slag, foundry sand, bottom ash and reclaimed asphalt pavement," Road Materials and Pavement Design, vol. 13, no. 4, pp. 691-712, 2012.

[19] L. R. de Rezende, J. C. de Carvalho, \& E. M. Palmeira, "The use of alternative and improved construction materials and geosynthetics in pavements," Elsevier Geo-Engineering Book Series, vol. 3, pp. 765-786, 2005. 
[20] Y. Huang, R. N. Bird, \& O. Heidrich, "A review of the use of recycled solid waste materials in asphalt pavements," Resources, Conservation and Recycling, vol. 52, no. 1, pp. 58-73, 2007.

[21] Z. N. Kalantar, M. R. Karim, \& A. Mahrez, "A review of using waste and virgin polymer in pavement," Construction and Building Materials, vol. 33, pp. 55-62, 2012.

[22] S. Karmakar \& T. K. Roy, "Effect of Waste Plastic and Waste Tires Ash on Mechanical Behavior of Bitumen," Journal of Materials in Civil Engineering, pp. 04016006, 2016.

[23] M. M. A. Aziz, M. T. Rahman, M. R. Hainin, \& W. A. W. A. Bakar, "An overview on alternative binders for flexible pavement," Construction and Building Materials, vol. 84, pp. 315-319, 2015.

[24] K. H. Moon, A. C. Falchetto, M. Marasteanu, \& M. Turos, "Using recycled asphalt materials as an alternative material in asphalt pavements," KSCE Journal of Civil Engineering, vol. 18, no. 1, pp. 149-159, 2014.

[25] S. Angelone, M. C. Casaux, M. Borghi, \& F. O. Martinez, "Green pavements: reuse of plastic waste in asphalt mixtures," Materials and Structures, pp. 1-11.

[26] A. K. Choudhary, J. N. Jha, \& K. S. Gill, "Utilization of plastic wastes for improving the sub-grades in flexible pavements," Paving Materials and Pavement Analysis, pp. 320-326, 2010.

[27] R. Vasudevan, A. R. C. Sekar, B. Sundarakannan, \& R. Velkennedy, "A technique to dispose waste plastics in an ecofriendly way-Application in construction of flexible pavements," Construction and Building Materials, vol. 28, no. 1, pp. 311-320, 2012.

[28] A. O. Sojobi, S. E. Nwobodo, \& O. J. Aladegboye, "Recycling of polyethylene terephthalate (PET) plastic bottle wastes in bituminous asphaltic concrete," Cogent engineering, 2016.

[29] M. S. Khan, S. Hossain, \& G. Kibria, "Slope Stabilization Using Recycled Plastic Pins," Journal of Performance of Constructed Facilities, 2015.

[30] A. Alvergue, M. Elseifi, L. N. Mohammad, S. B. Cooper Jr, \& S. Cooper III, "Laboratory evaluation of asphalt mixtures with reclaimed asphalt shingle prepared using the wet process," Road Materials and Pavement Design, vol. 15, no. 1, pp. 62-77, 2014.

[31] J. Yang, S. Ddamba, R. UL-Islam, M. Safiuddin, \& S. L. Tighe, "Investigation on use of recycled asphalt shingles in Ontario hot mix asphalt: a Canadian case study," Canadian Journal of Civil Engineering, vol. 41, no. 2, pp. 136-143, 2013.

[32] Y. Wang, G. Wang, \& Y. H. Ahn, "Effects of using recycled asphalt shingles in open-graded friction course on flexible pavement performance," Journal of Testing and Evaluation, vol. 42, no. 5, pp. 1-10, 2014.

[33] A. A. Cascione, R. C. Williams, \& J. Yu, "Performance testing of asphalt pavements with recycled asphalt shingles from multiple field trials," Construction and Building Materials, vol. 101, pp. 628-642, 2015.

[34] A. R. Abbas, U. A. Mannan, \& S. Dessouky, "Effect of recycled asphalt shingles on physical and chemical properties of virgin asphalt binders," Construction and Building Materials, vol. 45, pp. 162-172, 2013.

[35] N. P. Khosla, H. Nair, B. Visintine, \& G. Malpass, "Effect of reclaimed asphalt and virgin binder on rheological properties of binder blends," International Journal of Pavement Research and Technology, vol. 5, no. 5, pp. 317, 2012.

[36] I. L. Al-Qadi, M. Elseifi, \& S. H. Carpenter, "Reclaimed asphalt pavement-a literature review," Review No. FHWAICT-07-001, 2007.

[37] S. Hesp, "Interview with Lisa Laco. Superior Morning with Lisa Laco," CBC, 2015.

[38] N. S. Mashaan \& M. R. Karim, "Waste tyre rubber in asphalt pavement modification," Materials Research Innovations, vol. 18, no. S6, pp. S6-6, 2014.

[39] K. Krayushkina, O. Prentkovskis, A. Bieliatynskyi, \& R. Junevičius, "Use of steel slags in automobile road construction," Transport, vol. 27, no. 2, pp. 129-137, 2012.

[40] I. M. Asi, H. Y. Qasrawi, \& F. I. Shalabi, "Use of steel slag aggregate in asphalt concrete mixes," Canadian Journal of Civil Engineering, vol. 34, no. 8, pp. 902-911, 2007.

[41] S. A. Aiban, "Utilization of steel slag aggregate for road bases," Journal of Testing and Evaluation, vol. 34, no. 1, pp. $1-11,2005$.

[42] B. Saghafi, H. A. Nageim, P. VisuliosMPhil, \& N. Ghazireh, "Use of waste limestone dust and steel slag in UK highways type 1 unbound mixtures," in Proceedings of the Institution of Civil Engineers-Construction Materials, 2012, vol.. 166, no. 2, pp. 99-107.

[43] S. Agyeman \& S. I. Ampadu, "Exploring the techno-economic feasibility of mine rock waste utilisation in road works: The case of a mining deposit in Ghana," Waste Management \& Research, 2015. 
[44] S. Chandra, P. Kumar, \& B. A. Feyissa, "Use of marble dust in road construction," Road Materials and Pavement Design, vol. 3, no. 3, pp. 317-330, 2002.

[45] L. Ribeiro de Rezende, L. Ramos da Silveira, W. Lima de Araújo, \& M. Pereira da Luz, "Reuse of fine quarry wastes in pavement: Case study in Brazil," Journal of Materials in Civil Engineering, vol. 26, no. 8, pp. 05014003, 2013.

[46] [Online]. Available: http://www.afsinc.org/content.cfm?ItemNumber=7075.

[47] O. Yazoghli-Marzouk, N. Vulcano-Greullet, L. Cantegrit, L. Friteyre, \& A. Jullien, "Recycling foundry sand in road construction-field assessment," Construction and Building Materials, vol. 61, pp. 69-78, 2014.

[48] L. Li, C. H. Benson, T. B. Edil, B. Hatipoglu, \& O. Tastan, "Evaluation of recycled asphalt pavement material stabilized with fly ash," in Soil and Material Inputs for Mechanistic-Empirical Pavement Design, 2007, pp. 1-10.

[49] S. Saride, D. Avirneni, S. C. P. Javvadi, A. J. Puppala, \& L. R. Hoyos, "Evaluation of fly ash treated reclaimed asphalt pavement for base/subbase applications," Indian Geotechnical Journal, vol. 45, no. 4, pp. 401-411, 2015.

[50] A. Modarres \& P. Ayar, "Comparing the mechanical properties of cold recycled mixture containing coal waste additive and ordinary Portland cement," International Journal of Pavement Engineering, vol. 17, no. 3, pp. 211-224, 2016.

[51] S. Dimter, T. Rukavina, \& V. Dragèevic, "Strength properties of fly ash stabilized mixes," Road Materials and Pavement Design, vol. 12, no. 3, pp. 687-697, 2011.

[52] Y. R. Kim, I. Pinto, \& S. W. Park, "Experimental evaluation of anti-stripping additives in bituminous mixtures through multiple scale laboratory test results," Construction and Building Materials, vol. 29, pp. 386-393, 2012.

[53] M. Fall, T. Belem, S. Samb, M. Benzaazoua, "Experimental characterization of the stress-strain behaviour of cemented paste backfill," Journal of Materials Sciences, vol. 42, pp. 3914-3922, 2007.

[54] M. Fall and S. Samb, "Pore structure of cemented tailings materials under natural or accidental thermal loads," Journal of Material characterization, vol. 59, no. 5, pp. 598-605, 2008.

[55] O. Nasir and M. Fall, "Shear behaviour of cemented pastefill-rock interfaces," Engineering Geology, vol. 101, no. 3-4, pp. 146-143, 2008.

[56] M. Fall, J. C. Célestin, M. Pokharel, and M. Touré, "A contribution to understanding the effects of temperature on the mechanical properties of cemented mine backfill," Engineering Geology, vol. 14, no. 3-4, pp. 397-413, 2010.

[57] D. Wu, M. Fall, S-J. Cai, "Coupling temperature, cement hydration and rheological behaviour of cemented paste backfill structures," Minerals Engineering, vol. 42, pp. 76-87, 2013. 